Fourth International Symposium on Physics of Fluids (ISPF4)

International Journal of Modern Physics: Conference Series

Vol. 19 (2012) 270-275

(C) World Scientific Publishing Company

DOI: $10.1142 / \mathrm{S} 2010194512008859$

\title{
EXPERIMENTAL RESEARCH ON AEROELASTICITY OF A LARGE LENGTH TO DIAMETER RATIO PROJECTILE
}

\author{
WENJUN YI, DONGYANG SUN, JUNJIE TAN AND DANDAN YUAN \\ National Key Laboratory of Science and Technology on Ballistics, \\ Nanjing University of Science \& Technology, Nanjing, Jiangsu, China \\ wjy@mail.njust.edu.cn,dysunny86@sina.com,tjj@mail.njust.edu.cn,yuandandan@163.com
}

\begin{abstract}
In order to investigate the aeroelastic influences on the aerodynamic performance and flight stability of a large length to diameter ratio projectile, free-flight experiments on both the flexible and rigid projectile model are performed in our ballistic range. Many groups of shadowgraphs for these two kinds of projectiles during flight tests were taken and one of those typical results is shown. The projectile flight velocity, angle of attack and precession are obtained after the data procession. Moreover, the aerodynamic force and moment coefficients of two kinds of projectiles are presented, their aerodynamic performances and flight stability are compared and analyzed. Our results show that the flexible projectile has larger drag coefficient than the rigid. After the deformation, its lift to drag ratio decreases and its rotation moment increases obviously. The elastic deformation of the flexible projectile has remarkable influence on its flight stability which can induce the flight instability.
\end{abstract}

Keywords: Large length to diameter ratio projectile; aerodynamic performance; flight stability.

\section{Introduction}

Aircraft in flight may occur in the aeroelastic instability and violent aeroelastic response, especially for large length-diameter ratio, high supersonic flight shells. Under a certain aircraft pressure, its angle of attack incensement and aerodynamic winding moments increment promote with each other, which will lead to a big deformation of shell and its flight instability, even worse rupture or break. In design of aircraft, the importance of aeroelastic design has been long cognized, and a large number of aeroelastic design has been done to the aircraft wings. For projectiles with a long and thin body such as conventional artillery shell and rocket projectile, due to its large stiffness margin and rare aeroelastic accident, aeroelastic effects are often overlooked. During the 60 70 years, there are typical examples for damaged aircraft structure owing to their not taking the elastic issue into account when they are studying the large length-diameter ratio projectiles abroad. Recent years, we also encounter aeroelastic problems when we are research the ultra-long-range rocket projectiles in the domestic. For the aeroelastic problem of large length-diameter ratio and supersonic shell, we mainly carry out the analysis of the dynamic model flight stability.

In this paper, we use indoor ballistic range experimental facilities and adopt the model of length-diameter ratio shell with a slender body to have the range free-flight 
experiment, and study the influence on aerodynamic and flight stability of large lengthdiameter ratio exerted by aeroelasticity.

\section{Experimental Device and Projectile Model}

Ballistic range is an important facility used for measuring the free-flight characteristics of the ballistic initial segment of shell rockets, missiles and their models. The main test equipments in ballistic range are series of flash shadowgraphy stations, each station use orthogonal photography methods to obtain two shadow images of projectile. Through determination of data and images and calculations of space coordinates of location of projectile, the attitude angle and coordinates of the mass center can be drawn. The space reference coordinate system of ballistic range is the basis of determination of datas and images, and its basic function is to establish s set of coordinate of measurement and link the feature point of image of the projective achieved in the test to its corresponding space coordinates. In the experiment, we use flash shadowgraghy system composed of 24 spark flash shadowgraphic stations, time-acquisition system, space reference coordinate systems and meteorological measure system to have a comprehensive test of the parameters of state of motion, each flash shadowgraghic station has two sets of photographic light path orthogonal with each other.

The space orientation error of ballistic range is $\pm 1 \mathrm{~mm}$, but the elastic deformation of geometric similarity model of large length-diameter radio projectiles in flight is less than the space orientation error. According to the requirements for model in ballistic range experiment, though analysis, calculation and comparison of a variety of programs, we adopt a method of decreasing the stiffness of the model, increasing its flexibility and amplifying the horizontal elastic deformation of experimental model, through which an experimental model, though which a experimental model of flight projectile with springstructure is presented, its basic structure is shown in Fig. 1. In the figure, the experimental model is composed of the front body, the back bodies and tensile springs, between the two bodies there are tensile spins connecting the two segments. As the elastic coefficients of the tensile springs are far less than that of structure of pole, the test model under the action of the smaller torque can generate large elastic deformation.

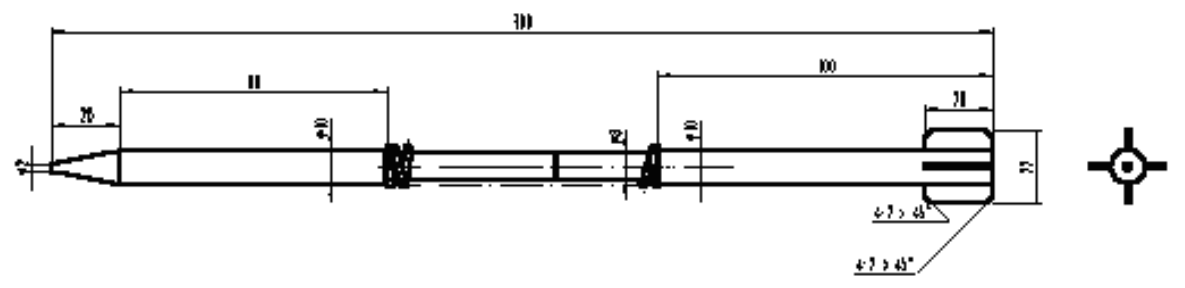

Fig.1. Experimental model of a typical large L/D ratio elastic projectile. 
In the test of experimental model of a typical large L/D ratio elastic projectile, in order to study the impact of elastic deformation of projectile, the experimental results of elastic model are needed to compare with which that of the stiff model. To this end, in accordance with the exterior structure of elastic model a rigid model is formulated for comparison experiment, as is shown in Fig. 2.

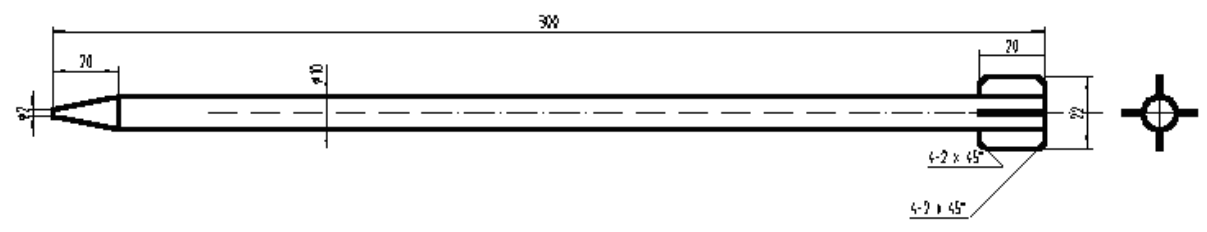

Fig.2. Experimental model of a typical large L/D ratio rigid projectile.

\section{Experimental Results}

Through testing the changing laws of both attitude angle and centroid coordinates of core-projectile after the model has left the muzzle, the comparison test between models of elastic and rigid projectile is to fit to calculate the main coefficients of aerodynamic forces and moments using experimental data to determine, the curves of flight velocity variation and nutation, and the impact of elastic deformation of large L/D ratio shell on flight motion is analyzed in the test.

The reliability of sabot discarded during firing and propellant scheme of several fire velocities for the two projectiles have been obtained by outdoor flight tests. According to the wavelength of trajectory of the two projectiles, disposal of measurement points of ballistic range test has been arranged. The location of measurement points refers to Table 1.

Table 1. Location of spark flash shadow photograph stations (m).

\begin{tabular}{ccccccccccccc}
\hline $\begin{array}{c}\text { Station } \\
\text { number }\end{array}$ & $x_{1}$ & $x_{2}$ & $x_{3}$ & $x_{4}$ & $x_{5}$ & $x_{6}$ & $x_{7}$ & $x_{8}$ & $x_{9}$ & $x_{10}$ & $x_{11}$ & $x_{12}$ \\
\hline $\begin{array}{r}\text { distance } \\
\text { Station }\end{array}$ & 21.80 & 23.84 & 25.82 & 27.96 & 29.85 & 31.88 & 33.92 & 35.94 & 38.91 & 41.95 & 44.98 & 47.97 \\
number & $x_{13}$ & $x_{14}$ & $x_{15}$ & $x_{16}$ & $x_{17}$ & $x_{18}$ & $x_{19}$ & $x_{20}$ & $x_{21}$ & $x_{22}$ & $x_{23}$ & $x_{24}$ \\
distance & 50.98 & 53.97 & 57.03 & 60.51 & 65.03 & 70.06 & 74.09 & 80.07 & 85.10 & 90.10 & 95.10 & 100.16 \\
\hline
\end{tabular}

In the test, three groups of models of projectiles are shot, from which relatively comprehensive orthogonal shadow images of large L/D ratio models of projectiles in free-flight are achieved, as is shown in Figs. 3 and 4. 

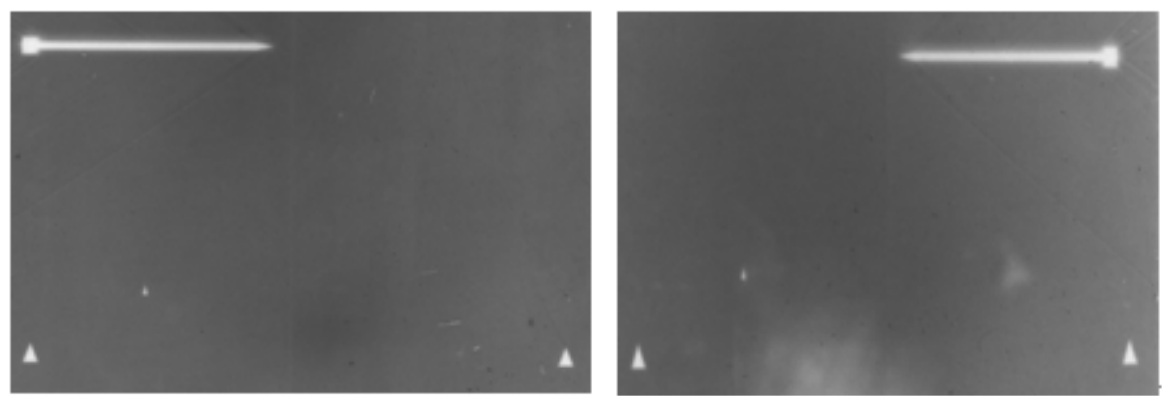

Fig. 3. The flash shadowgraph of rigid model at the 5th station projectile.

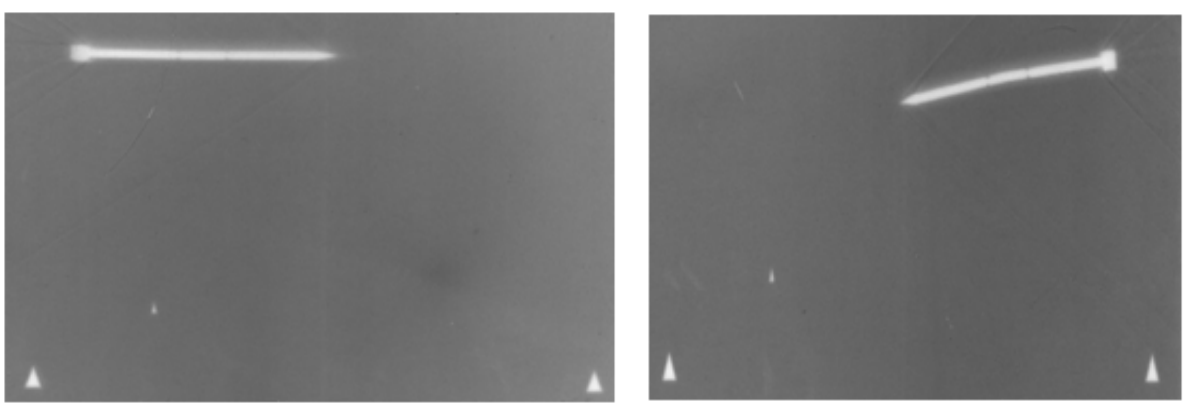

(a) $5^{\text {th }}$ station flash shadowgraph.

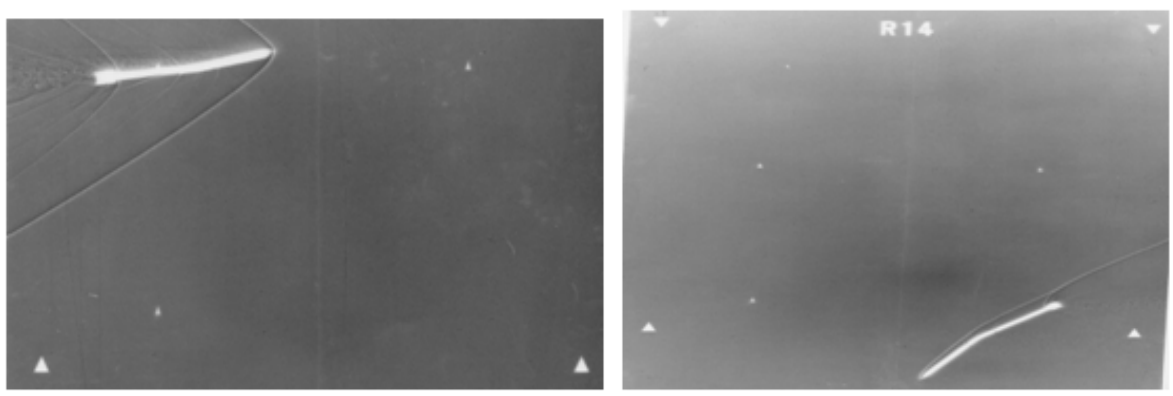

(b) 14th station flash shadowgraph.
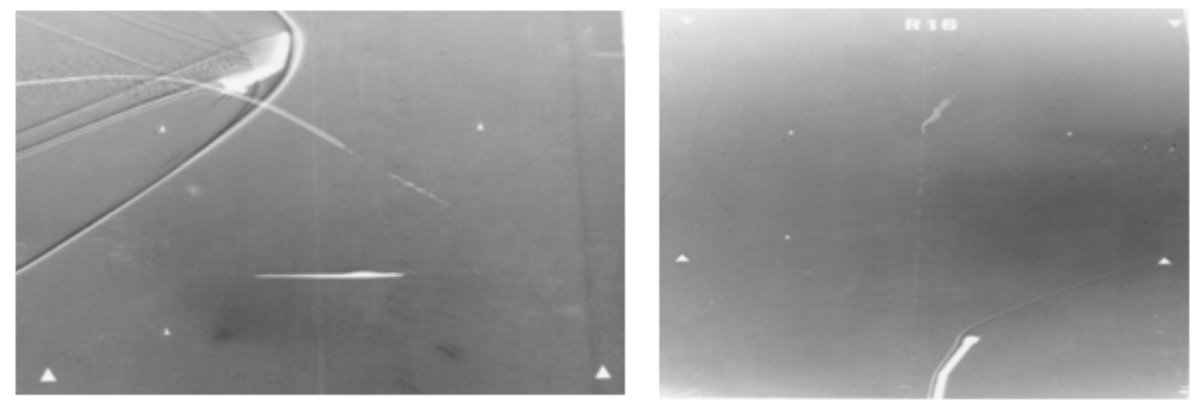

(c) 16th station flash shadowgraph.

Fig. 4. The flash shadowgraph of the flexible model of projectile. 


\section{Data Processing and Results Analysis}

In test of free-flight of the projectile, the parameters of motion such as the coordinates of the mass center, flight time, attitude angle and spin angle can be measured when projectile passes through each measurement characteristic point. Other corresponding parameters of motion can be calculated with a set of acceptable aerodynamic coefficients and initial conditions. The task is to minimize the sum of the weighted square of the residuals between theoretical calculation results and experimental data.

Through processing and determination of the orthogonal shadowgraph and data processing for the model of large L/D ratio projectile, flight velocity $(\mathrm{V})$, attack angle $(\delta)$, precession(v) and flight trajectory of centroid $(\mathrm{x}, \mathrm{y}, \mathrm{z})$ of both rigid and elastic models of shells can be obtained. The curve of attack angle is shown in Figs. 5 and 6. The main coefficients of aerodynamic forces and moments of large L/D ratio rocket projectile after fitting calculation are shown in Table 2.

Table 2. The results of data processing of the both projectiles.

\begin{tabular}{ccccccc}
\hline & 1\# Rigid & 2\# Rigid & 3\# Flexible & 4\# Flexible & 5\# Flexible & 6\# Flexible \\
$c_{x}$ & 0.461 & 0.467 & 0.592 & 0.622 & 0.774 & 0.73 \\
$c_{y}^{\alpha}$ & 7.62 & 7.43 & 7.59 & 7.66 & 7.18 & 7.34 \\
$m_{z}^{\alpha}$ & -8.93 & -8.13 & -8.47 & -8.72 & -8.34 & -8.67 \\
$V_{o}$ & 649.2 & 643.5 & 647.6 & 649.3 & 646.7 & 648.3 \\
$\lambda$ & 44.8 & 47.3 & 48.6 & 44.5 & 48.3 & 46.2 \\
$\delta_{m}$ & 5.4 & 5.6 & 7.8 & 7.2 & 10.7 & 9.5 \\
$L_{m} / \mathrm{mm}$ & 0 & 0 & 3.2 & 3.1 & 5.6 & 4.7 \\
\hline
\end{tabular}

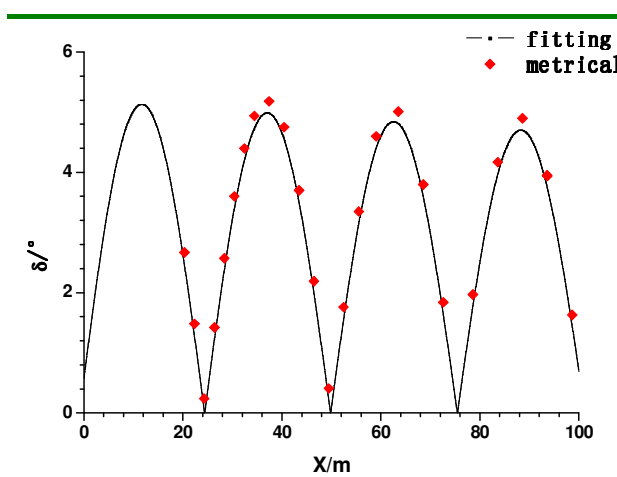

Fig. 5. The attach angle of the rigid projectile.

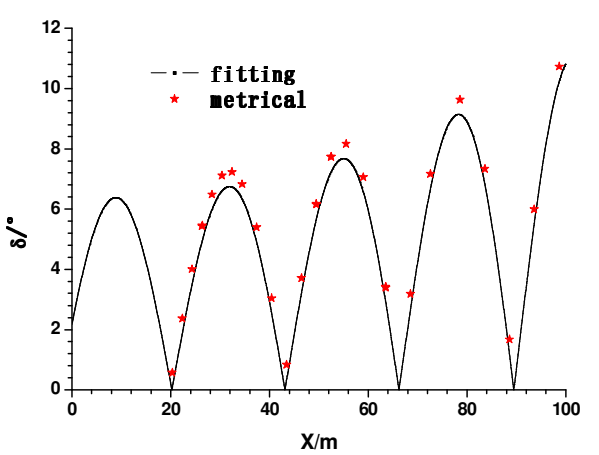

Fig. 6. The attach angle of the flexible projectile.

From the experimental photos and results we can see that:

(a) From the processing results of the experimental data, we can conclude that the drag coefficient of model of large L/D ratio elastic shell is significantly larger than that of 
the rigid shell, which shows that the elastic deformation of large L/D ratio shell has a great impact on projectile aerodynamic characteristics;

(b) In the ballistic range experiment, according to the flash shadowgraphs and curve of nutation after data processing, it is obvious that elastic deformation of the large L/D ratio shell exert a significant influence on flight stability, leading to flight instability of the shell.

\section{References}

1. V. L. Alley and A. Harper-Gerring, An analysis of aeroelastic divergence in unguided vehicles, NASA TND-3281, 1966.

2. C. P. Young, Analysis of the aeroelastic divergence of two experimental unguided launch vehicles, NASA TND-4846, 1968.

3. P. Y. Clarence, AIAA, 70-1397, 1970.

4. D. M. Platus, AIAA, 89-3393, 1989.

5. C. Guo, J. Dong, Q. Yang and J. Li, Aero. Comput. Tech. 36, 40 (2006).

6. W. Zhang and Z. Ye, Chinese J. Theo. App. Mech. 37, 632 (2005).

7. C. Zhang, W. Zhang and Z. Ye, Eng. Mech. 24, 22 (2007).

8. Z.-Q. Wan, C. Tang and C. Yang, Acta Aero. Astro. Sin. 23, 342 (2002). 